\title{
Effectiveness of lidocaine/prilocaine cream on cardiovascular reactions from endotracheal intubation and cough events during recovery period of older patients under general anesthesia: prospective, randomized placebo-controlled study
}

Linsheng Lv ${ }^{1+}$, Lei Yan ${ }^{2+}$, Xun Liu ${ }^{3 *}$ and Miaoxia Chen ${ }^{4 *}$

\begin{abstract}
Background: Endotracheal intubation is known to pose significant physiological, pharmacokinetic, and dynamic changes and postoperative respiratory complications in patients under general anesthesia.

Method: An RCT trial was organized by the Third Affiliated Hospital at Sun Yat-sen University, China. Patients were eligible for inclusion in the trial if they were over 60 years old and had upper-abdominal surgery during the induction of anesthesia and had enrolled in endotracheal intubations. The primary end point included cardiovascular reactions during the induction of anesthesia and endotracheal intubations and cough events during the recovery period. In the test group, $2 \mathrm{~g}$ of lidocaine/prilocaine cream (and in the control group, $2 \mathrm{~g}$ of Vaseline) were laid over the surface of the tracheal tube cuff.

Results: The systolic blood pressure ( $F$ value $=62.271, p<0.001$ ), diastolic blood pressure ( $F$ value $=150.875, p<$ 0.001 ), and heart rate ( $F$ value $=75.627, p<0.001$ ) of the test group were significantly lower than the control group. Cough events during the recovery period in the test group were better (spontaneous cough, $X^{2}$ value $=10.591, p<$ 0.001 ; induced cough, $x^{2}$ value $=10.806, p<0.001$ ).
\end{abstract}

Conclusion: In older patients, coughing and cardiovascular reactions under anesthesia and endotracheal intubations were reduced, as a result of using lidocaine/prilocaine cream on the surface of the tracheal tube cuff.

Trial registration: International Clinical Trials Network NCT02017392, 2013-12-16.

\footnotetext{
*Correspondence: naturestyle@163.com; 1109986151@qq.com

${ }^{\dagger}$ Lv Linsheng and Yan Lei contributed equally to this work.

${ }^{3}$ Division of Nephrology, the third Affiliated Hospital of Sun Yat-sen

University, Guangzhou 510630, Guangdong, China

${ }^{4}$ Nursing Department, the third Affiliated Hospital of Sun Yat-sen University, Guangzhou 510630, Guangdong, China

Full list of author information is available at the end of the article
}

(c) The Author(s). 2020, corrected publication 2020. Open Access This article is licensed under a Creative Commons Attribution 4.0 International License, which permits use, sharing, adaptation, distribution and reproduction in any medium or format, as long as you give appropriate credit to the original author(s) and the source, provide a link to the Creative Commons licence, and indicate if changes were made. The images or other third party material in this article are included in the article's Creative Commons licence, unless indicated otherwise in a credit line to the material. If material is not included in the article's Creative Commons licence and your intended use is not permitted by statutory regulation or exceeds the permitted use, you will need to obtain permission directly from the copyright holder. To view a copy of this licence, visit http://creativecommons.org/ licenses/by/4.0/. The Creative Commons Public Domain Dedication waiver (http://creativecommons.org/publicdomain/zero/1. 0/) applies to the data made available in this article, unless otherwise stated in a credit line to the data. 


\section{Background}

Endotracheal intubation has been shown to cause significant physiological, pharmacokinetic, and dynamic changes, along with postoperative respiratory complications in patients under general anesthesia [1]. Transient hemodynamic changes during these periods increase myocardial oxygen consumption, leading to myocardial ischemia. This can increase the risk of cardiovascular and cerebrovascular diseases, and of morbidity and mortality, in older patients under general anesthesia. Stellate ganglion block can restrain the stress response from inducing anesthesia and endotracheal intubations [2]. Several alternative approaches to mitigating this response have also been reported, such as the administration of esmolol, labetalol, nitroglycerin, clonidineare, and lidocaine [3-7]. However, stellate ganglion blocks are invasive and the alternative approaches are not always satisfactory.

Lidocaine/prilocaine cream (a eutectic mixture of lidocaine $25 \mathrm{mg} / \mathrm{mL}$ and prilocaine $25 \mathrm{mg} / \mathrm{mL}$ ) is widely used as a topical anesthetic [8-11]. To our knowledge, however, no high quality randomized controlled study has been conducted to investigate the use of lidocaine/ prilocaine cream to prevent cardiovascular stress responses in older patients undergoing tracheal intubation under general anesthesia. Our central hypothesis is that lidocaine/prilocaine can be used substantially in tracheal intubation of older patients under general anesthesia. The purpose of our study was to carry out an RCT trial on this application. The results offer accurate evidence for the local use of lidocaine/prilocaine cream in tracheal intubation of older patients under general anesthesia, to facilitate the postoperative rehabilitation and quality of life of these patients.

\section{Methods}

\section{Trial design}

The RCT trial was organized by the Third Affiliated Hospital at Sun Yat-sen University, China. The trial was conducted according to the CONSORT-2010 guidelines. The study was approved by the Review Board of the Third Affiliated Hospital at Sun Yet-sen University ([2013]2-85). All subjects provided written informed consent before the trial. Underlying data are available in accordance with the Management of Human Genetic Resources in China.

\section{Participants and setting}

Patients were included in the trial if they were over 60 years old and scheduled for upper abdominal surgery under general anesthesia using endotracheal tube intubation from August 2015 through December 2018. The major exclusion criteria were the following: allergies to lidocaine, prilocaine, or any other ingredients in the test product; ischemic heart disease or advanced chronic kidney disease; younger than 60 years old; American Society of Anesthesiologists (ASA) Grade IV. We randomly assigned older patients to either lidocaine/prilocaine cream treatment or a placebo (Vaseline) at a 1:1 ratio. The primary end point included cardiovascular reactions during the induction of anesthesia, along with endotracheal intubations and cough events during the recovery period. Figure 1 shows a flowchart for the assignment of participants in the study.

\section{Intervention}

Nurses inflated the endotracheal tube. According to the random number table, in the test group, off-label use of $2 \mathrm{~g}$ of lidocaine/prilocaine cream (and in the control group, $2 \mathrm{~g}$ of Vaseline cream) were laid over the surface of the tracheal tube cuff. After ventilation, the anesthesiologists placed the endotracheal tube and fixed the endotracheal tube with air. Both the patients and the investigators were unaware of the trial-group assignments. Before tracheal intubation, anesthetics was used and unconscious intubation was carried out. The depth of anesthesia was measured by the bispectral index (BIS). Fentanyl was used as the induction agent according to the sex, weight, and ASA rating of the patients. Benzene sulfuro acted as the muscle relaxant and its dosage was based on the weight and situation of the patients during the operation.

\section{Parameter measurement}

Cardiovascular reaction during the induction of anesthesia: systolic blood pressure (SBP) (mm $\mathrm{Hg})$, diastolic blood pressure (DBP) (mm Hg), heart rate (HR) (beats/min), and cough reaction. Coughing that occurred during extubation was defined as induced cough. The SBP, DBP, and HR were measured with a monitor.

\section{Sample size calculation}

According to the pretest analysis of 10 patients in each group, we set $\alpha=0.05$ and $\beta=0.20$, with a sample drop rate of 20\%. Using Open Epi Version 2 [12], we calculated the minimum sample size of 125 cases in each group (a total of 250 cases).

\section{Statistical analysis}

The measurements were calculated as the mean $( \pm$ standard deviation). An independent $t$-test was used to compare the groups. Further, a chi-squared test was used to compare the categorized data in the groups. An analysis of variance of the repeated measurement data was conducted to compare the data. We set $p<0.05$ as statistically significant. $\mathrm{R}$ version 3.0 .2 was used to process the data. 


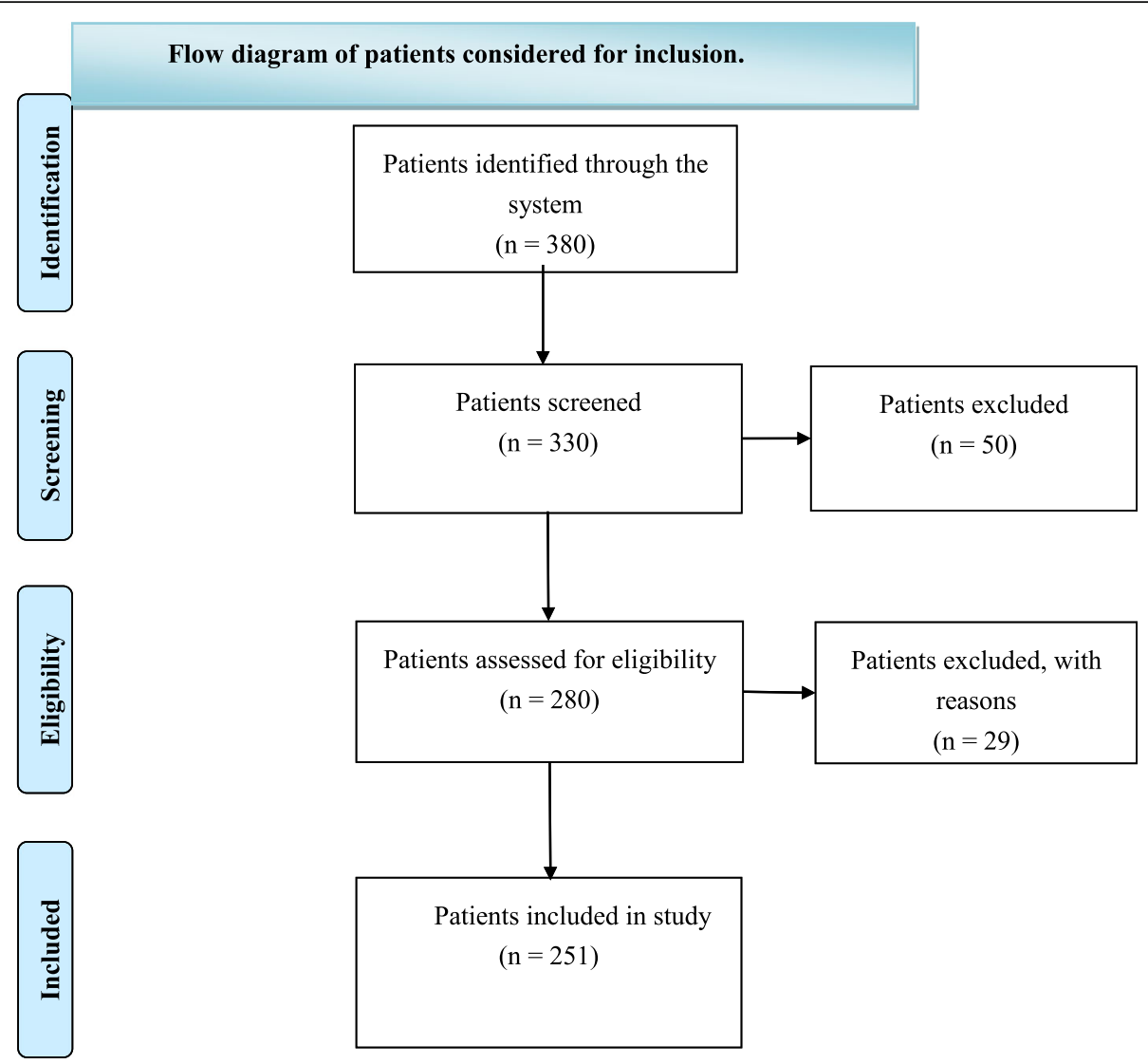

Fig. 1 Flow diagram of patients considered for inclusion.

\section{Results}

\section{Patients}

A total of 251 older patients at the Third Affiliated Hospital at Sun Yet-sen University were enrolled in the randomized trial. There were no significant differences in the baseline characteristics (such as age, sex, ASA rating, operation time and depth of anesthesia) of the patients between the two groups (Table 1). Both groups were anesthetized with general anesthesia by tracheal intubation.

Table 1 Patient Characteristics

\begin{tabular}{lllll}
\hline & Test Group & Control Group & $\mathrm{t} / \mathrm{X}^{2}$ Value & $P$ Value \\
\hline Age (years) & $70.3 \pm 5.9$ & $70.4 \pm 5.2$ & -0.155 & 0.877 \\
Sex (male n (\%)) & $76(53.9)$ & $65(46.1)$ & 2.163 & 0.141 \\
ASA I (\%) & $44(51.8)$ & $41(48.2)$ & 0.752 & 0.687 \\
ASA II(\%) & $38(52.1)$ & $35(47.9)$ & & \\
ASA III(\%) & $43(46.2)$ & $50(53.8)$ & & \\
Operation time (hours) & $1.6 \pm 0.6$ & $1.6 \pm 0.6$ & $\mathrm{t}=-0.693$ & 0.489 \\
Depth of anaesthesia & $48.3 \pm 4.4$ & $47.6 \pm 4.5$ & $\mathrm{t}=1.279$ & 0.202 \\
\hline
\end{tabular}

\section{Primary outcomes}

The systolic blood pressure (F value $=62.271, p<0.001$ ), DBP (F value $=150.875, P<0.001)$ and heart rate $(\mathrm{F}$ value $=75.627, P=<0.001)$ of the test group were significantly lower than the control group (Table 2).

Cough events in recovery period in the test group were better (Spontaneous cough $\left(\chi^{2}\right.$ value $\left.=10.591, P=0.001\right)$; Induces cough $\left(\chi^{2}\right.$ value $\left.=10.806, P=0.001\right)$ ) (Table 3$)$.

\section{Discussion}

To our knowledge, this study for the first time demonstrated in a high quality RCT that there are improvements from the use of lidocaine/prilocaine cream on the surface of the tracheal tube cuff in older patients in terms of postoperative coughing and cardiovascular reactions during the induction of anesthesia. Our results are similar to those by Chen [2]. Furthermore, our study found that cough events during the recovery period improved in the test group. These findings may lead to beneficial effects on cardiovascular reactions in the course of endotracheal intubation.

During tracheal intubation, blood pressure often rises sharply, and systolic blood pressure rises by $45 \mathrm{mmHg}$ 
Table 2 Comparison of cardiovascular reaction and heart rate between two groups

\begin{tabular}{|c|c|c|c|c|c|c|c|c|c|c|}
\hline & Group & $\begin{array}{l}\text { Before } \\
\text { induction }\end{array}$ & $\begin{array}{l}\text { Before } \\
\text { intubation }\end{array}$ & $\begin{array}{l}\text { Instant } \\
\text { intubation }\end{array}$ & $\begin{array}{l}1 \text { min after } \\
\text { intubation }\end{array}$ & $\begin{array}{l}\text { Instant } \\
\text { extubation }\end{array}$ & $\begin{array}{l}1 \text { min after } \\
\text { extubation }\end{array}$ & $\begin{array}{l}3 \text { min after } \\
\text { extubation }\end{array}$ & F Value & $P$ Value \\
\hline \multirow[t]{2}{*}{ SBP $(\mathrm{mm} \mathrm{Hg})$} & Test group & $141.8 \pm 5.9$ & $131.8 \pm 5.3$ & $128.8 \pm 4.8$ & $126.8 \pm 4.6$ & $123.8 \pm 3.9$ & $120.8 \pm 3.7$ & $119.9 \pm 3.4$ & 62.271 & $<0.0001$ \\
\hline & Control group & $139.7 \pm 5.4$ & $133.8 \pm 4.9$ & $131.8 \pm 4.6$ & $130.8 \pm 4.2$ & $131.9 \pm 3.7$ & $129.8 \pm 3.5$ & $127.9 \pm 3.3$ & & \\
\hline \multirow[t]{2}{*}{$\mathrm{DBP}(\mathrm{mm} \mathrm{Hg})$} & Test group & $81.8 \pm 5.9$ & $74.8 \pm 5.3$ & $73.8 \pm 4.8$ & $74.8 \pm 4.6$ & $69.8 \pm 3.9$ & $71.8 \pm 3.7$ & $69.9 \pm 3.4$ & 150.875 & $<0.0001$ \\
\hline & Control group & $82.7 \pm 5.4$ & $75.8 \pm 4.9$ & $81.8 \pm 4.6$ & $80.8 \pm 4.2$ & $82.9 \pm 3.7$ & $80.8 \pm 3.5$ & $79.9 \pm 3.3$ & & \\
\hline \multirow[t]{2}{*}{ HR (beat/min) } & Test group & $85.8 \pm 5.9$ & $77.8 \pm 5.3$ & $82.8 \pm 4.8$ & $80.8 \pm 4.6$ & $82.8 \pm 3.9$ & $80.8 \pm 3.7$ & $82.9 \pm 3.4$ & 75.627 & $<0.000$ \\
\hline & Control group & $85.7 \pm 5.4$ & $77.8 \pm 4.9$ & $89.8 \pm 4.6$ & $88.8 \pm 4.2$ & $89.9 \pm 3.7$ & $88.8 \pm 3.5$ & $86.9 \pm 3.3$ & & \\
\hline
\end{tabular}

${ }^{\mathrm{a} S B P}$ : systolic blood pressure; DBP: diastolic blood pressure; HR: heart rate; min: minute

on average. Further, tachycardia and other circulatory system reactions are common, and they are collectively referred to as the intubation stress response. Generally, the time is short $(3-5 \mathrm{~min})$. However, patients with an abnormal cardiovascular and cerebrovascular system, especially older patients, face life-threatening reactions that should be minimized or avoided completely [13]. Lidocaine and prilocaine are phthalocaine local anesthetics. Lidocaine is fast-acting, with wide dispersion, strong penetration, and no obvious vasodilator effect. The structure of prilocaine is similar to that of lidocaine and it decomposes easily, such that its toxicity is relatively rare. Its onset time is slower than that of lidocaine, and its duration is slightly longer. The combined application of the two drugs can enhance the anesthetic effect. Moreover, it takes effect quickly with a long duration. It has antimicrobial properties of intact human skin flora as a topical anesthesia before vascular access, and reduces the pain of venipuncture in hemodialysis patients [8-11].

The strength of our paper lies in its high-quality design. However, there are limitations: 1) the total observation period was relatively short, and indeed a longer observation time may be better; 2) although our treatment was very safe, we did not extensively analyze side effects; 3 ) we did not set up clinically relevant cutoffs regarding blood pressure; 4) we did not study significant postoperative symptoms such as postoperative sore throat or difficulty swallowing in this paper; and 5) the coughing intensity was not measured.

\section{Conclusion}

We found that during the induction of anesthesia in older patients, cough reactions and cardiovascular

Table 3 Comparison of cough events during recovery period between two groups

\begin{tabular}{lllll}
\hline & $\begin{array}{l}\text { Treatment } \\
\text { Group }\end{array}$ & $\begin{array}{l}\text { Control } \\
\text { Group }\end{array}$ & $x^{2}$ Value & $P$ Value \\
\hline Spontaneous cough [case (\%)] & $4(3.1)$ & $13(10.7)$ & 10.591 & 0.001 \\
Induces cough [case (\%)] & $8(6.4)$ & $27(21.4)$ & 10.806 & 0.001 \\
\hline
\end{tabular}

reactions from endotracheal intubations improved as a result of using lidocaine/prilocaine cream on the surface of the tracheal tube cuff, which may decrease the risk of cardiovascular and cerebrovascular diseases in these patients.

\section{Abbreviations}

RCT: Randomized controlled study; SBP: Systolic blood pressure; DBP: Diastolic blood pressure; HR: Heart rate

\section{Acknowledgements}

We would like to thank all the doctors, nurses, technicians, and patients involved in this study for their cooperation.

The authors thank Dr. David Cushley from International Science Editing, Clare, Ireland for assistance with the English version of the manuscript.

\section{Authors' contributions}

Author Contributions: LLS and CMX researched data. LLS, YL and LX wrote manuscript. LX and CMX reviewed/edited manuscript. LX and CMX contributed to discussion. The author(s) read and approved the final manuscript.

\section{Funding}

Project 81370866 supported by the National Natural Science Foundation of China in the design of the study, interpretation of data, and in writing the manuscript.

\section{Availability of data and materials}

The database used and/or analyzed during the current study are available from the corresponding author (Prof. Xun Liu, Division of Nephrology, the third Affiliated Hospital of Sun Yat-sen University, Guangzhou 510630, China. Tel: + 860208525 3115, e-mail: naturestyle@163.com) on reasonable request.

\section{Ethics approval and consent to participate}

The study was approved by the Review Board of the Third Affiliated Hospital at Sun Yet-sen University ([2013]2-85). All subjects provided written informed consent before the trial.

\section{Consent for publication}

Not applicable.

\section{Competing interests}

The authors declare that they have no competing interests.

\section{Author details}

'Operation Room, the third Affiliated Hospital of Sun Yat-sen University, Guangzhou 510630, Guangdong, China. ${ }^{2}$ Shanghai Shyndec Pharmaceutical Co., Ltd, Shanghai 600420, China. ${ }^{3}$ Division of Nephrology, the third Affiliated Hospital of Sun Yat-sen University, Guangzhou 510630, Guangdong, China. ${ }^{4}$ Nursing Department, the third Affiliated Hospital of Sun Yat-sen University, Guangzhou 510630, Guangdong, China. 
Received: 28 February 2020 Accepted: 22 April 2020

Published online: 27 July 2020

\section{References}

1. Beyer K, Taffé P, Halfon P, Pittet V, Pichard S, Haller G, Burnand B, ADS study group. Hypertension and intra-operative incidents: a multicentre study of 125,000 surgical procedures in Swiss hospitals. Anaesthesia. 2009;64(5):494-502.

2. Chen YQ, Jin XJ, Liu ZF, Zhu MF. Effects of stellate ganglion block on cardiovascular reaction and heart rate variability in elderly patients during anesthesia induction and endotracheal intubation. J Clin Anesth. 2015;27(2): $140-5$.

3. Chung KS, Sinatra RS, Chung JH. The effect of an intermediate dose of labetalol on heart rate and blood pressure responses to laryngoscopy and intubation. J Clin Anesth. 1992;4(1):11-5.

4. Zalunardo MP, Zollinger A, Szelloe P, Spahn DR, Seifert B, Pasch T. Cardiovascular stress protection following anesthesia induction. Comparison of clonidine and esmolol. Anaesthesist. 2001;50(1):21-5.

5. Firoozbakhsh F, Mohammadi FH, Safari S, Khashayar P. The effect of intravenous nitroglycerine on blood pressure during intubation. Middle East J Anesthesiol. 2008;19(4):859-67.

6. Menigaux C, Guignard B, Adam F, Sessler DI, Joly V, Chauvin M. Esmolol prevents movement and attenuates the BIS response to orotracheal intubation. Br J Anaesth. 2002;89(6):857-62.

7. Sun HL, Wu TJ, Ng CC, Chien CC, Huang CC, Chie WC. Efficacy of oropharyngeal lidocaine instillation on hemodynamic responses to orotracheal intubation. J Clin Anesth. 2009;21(2):103-7.

8. Batai I, Bogar L, Juhasz V, Batai R, Kerenyi M. A comparison of the antimicrobial property of lidocaine/prilocaine cream (EMLA) and an alcoholbased disinfectant on intact human skin flora. Anesth Analg. 2009;108(2): 666-8.

9. Sawyer J, Febbraro S, Masud S, Ashburn MA, Campbell JC. Heated lidocaine/ tetracaine patch (Synera, Rapydan) compared with lidocaine/prilocaine cream (EMLA) for topical anaesthesia before vascular access. Br J Anaesth. 2009;102(2):210-5.

10. Çelik G, Özbek O, Yılmaz M, Duman I, Özbek S, Apiliogullari S. Vapocoolant spray vs lidocaine/prilocaine cream for reducing the pain of venipuncture in hemodialysis patients: a randomized, placebo-controlled, crossover study. Int J Med Sci. 2011;8(7):623-7.

11. Keiji F, Hiroki A, Yasuo I, Hitoshi Y. Comparison of the pain-reducing effects of EMLA cream and of lidocaine tape during arteriovenous fistula puncture in patientsundergoing hemodialysis: A multi-center, open-label, randomized crossover trial. PLoS One. 2020;15(3):e0230372.

12. Dean AG, Sullivan KM, Soe MM. OpenEpi: Open Source Epidemiologic Statistics for Public Health, www.OpenEpi.com, updated 2013/04/06 Accessed 26 Apr 2020.

13. Ko BJ, Oh JN, Lee JH, Choi SR, Lee SC, Chung CJ. Comparison of effects of fentanyl and remifentanil on hemodynamic response to endotrachealintubation and myoclonus in elderly patients with etomidate induction. Korean J Anesthesiol. 2013;64(1):12-8.

\section{Publisher's Note}

Springer Nature remains neutral with regard to jurisdictional claims in published maps and institutional affiliations.

Ready to submit your research? Choose BMC and benefit from:

- fast, convenient online submission

- thorough peer review by experienced researchers in your field

- rapid publication on acceptance

- support for research data, including large and complex data types

- gold Open Access which fosters wider collaboration and increased citations

- maximum visibility for your research: over $100 \mathrm{M}$ website views per year

At BMC, research is always in progress.

Learn more biomedcentral.com/submissions 